\title{
Climate change in Africa: Evidence, mechanisms and impacts - Past and present
}

\author{
Rachid Cheddadi', I. Bouimetarhan², M. Carré ${ }^{3}$, A. Rhoujjati ${ }^{4}$, A. Benkaddour ${ }^{4}$ and M. Nourelbait ${ }^{1}$
}

Marrakesh, Morocco, 6-11 November 2017

Climate changes in Africa have a tremendous impact on ecosystems and human societies. Climate change-related risks are aggravated in Africa by the deficient data availability and research efforts which create major knowledge gaps and uncertainties.

In an attempt to build synergy and promote climate change research in Africa, the multidisciplinary conference CCA2017 (Climate Change in Africa, vulpesproject.wix.com/ workshop) was organized at the Cadi Ayyad University of Marrakesh.

The primary goal was to gather scientists from complementary disciplines including Earth sciences, (paleo-)oceanography, (paleo-)climatology, climate modeling, ecology, and archaeology, for a multidisciplinary assessment of the latest results and to start discussions related to climate change and its

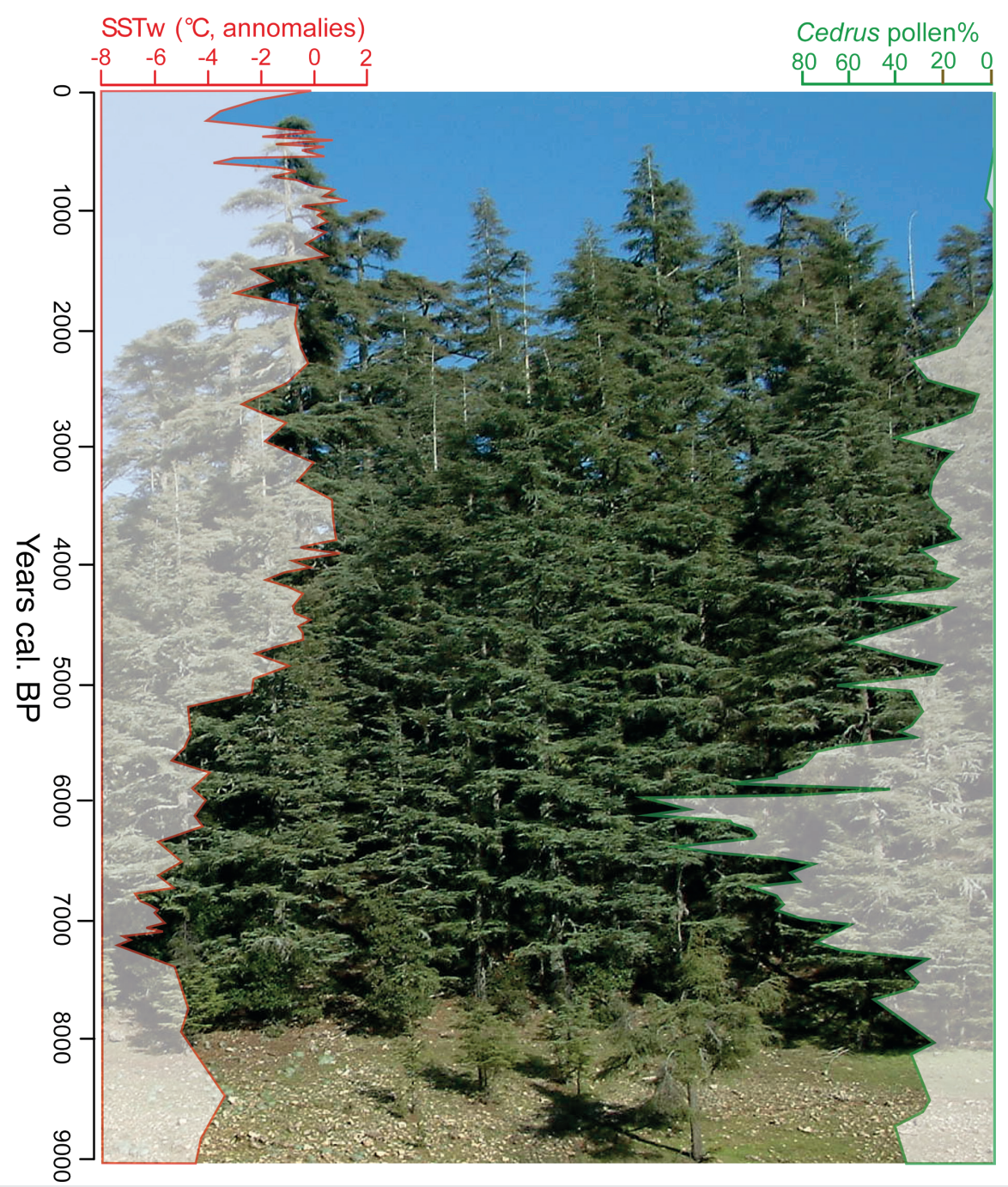

Figure 1: Will the ongoing climate change in Africa lead to an extinction of some endemic species (Cheddadi et al. 2017)?

impacts, from past natural variability to modern changes and future projections.

CCA2017 was attended by 80 delegates from 20 countries including eight African countries (Algeria, Benin, Cameroon, Congo, Morocco, Senegal, South Africa and Tunisia). Travel support was offered by PAGES for three African early-career scientists who presentations. The conference consisted of five sessions: (1) on climate change mechaforcing and inter-annual rainfall variability, extreme precipitation over Africa, dust predicting the Sahel summer rainfall, and the variability of the West African monsoon; (2) dedicated to the climate impacts on ecoand agro-systems. This session gathered presentations on the cultural resilience of the presented their work in both posters and oral nisms in Africa including links between orbital fluctuations during the African Humid Period,

\section{AFFILIATIONS}

IISEM, University of Montpellier, France 2MARUM, University of Bremen, Germany ${ }^{3}$ LOCEAN Laboratory (CNRS-IRD-MNHN), Sorbonne University, Paris, France

"Faculty of Sciences and Techniques, Cadi Ayyad University, Marrakech, Morocco

\section{CONTACT}

Rachid Cheddadi: cheddadi.rc@gmail.com 